the question of whether or not a child was ever breast fed is not subject to major recall error. The length of time elapsed before obtaining data was less for our paediatric patients than in studies in adults. ${ }^{45}$

It is possible that the aetiologies of Crohn's disease and ulcerative colitis are distinct and that breast feeding exerts a protective effect only in Crohn's disease. Alternatively, a small protective effect of breast feeding in preventing later ulcerative colitis may not have been identified by the number of patients entered into this study (type II error).

As in our previous study of childhood Crohn's disease, diarrhoeal illness during infancy was identified as an independent risk factor for subsequent development of ulcerative colitis. Infectious diarrhoea could increase exposure of the enteric immune system to luminal antigens,' leading to enhanced or altered immune responses against dietary and microbial antigens later in life. It is possible, however, that recall bias accounted for the difference observed between the two groups as parents might remember previous intestinal symptoms more often among their affected children. The intrafamilial analysis we used might account for the different outcome from that in other studies. ${ }^{34}$ Additional data are required to clarify the influence of events in early childhood on the development of inflammatory bowel diseases.

This work was supported by a grant from the Canadian Foundation for Ileitis and Colitis. PS received a career scientist award from the Ontario Ministry of Health, and SK received a clinical research fellowship from Nordic Laboratories.

1 Chandra RK. Long-term health implications of mode of infant feeding. Nutr Res 1989;9:1-3.

2 Koletzko S, Sherman P, Corey M, Griffiths A, Smith C. Role of infant feeding practices in development of Crohn's disease in childhood. BMF 1989;298: ज़ $1617-8$.

3 Gilat T, Hacohen D, Lilos P, Langman MJS. Childhood factors in ulcerative colitis and Crohn's disease: an international cooperative study. Scand $\mathcal{F}$ 罗
Gastroenterol 1987;22:1009-24.

4 Whorwell PJ, Holdstock G, Whorwell GM, Wright R. Bottle feeding, early gastroenteritis, and inflammatory bowel disease. BMF 1979;i:382.

5 Acheson ED, Truelove SC. Early weaning in the aetiology of ulcerative colitis: a study of feeding in infancy in cases and controls. BMJ 1961;ii:929-33.

(Accepted 10 April 1991)

\section{Somatic component to myocardial infarction: three year follow up}

\section{A S Nicholas, D A DeBias, C H Greene}

\section{Philadelphia College of} Osteopathic Medicine, Philadelphia, Pennsylvania, United States 19131

A S Nicholas, Do, professor of osteopathic principles and practice

D A DeBias, PHD, professor of physiology and

pharmacology

C H Greene, PHD, professor of physiology

Correspondence to:

Professor DeBias.

$B M \mathcal{J} 1991 ; 302: 1581$ myocardial damage resolved.

\section{Patients, methods, and results} or too debilitated to participate.
In an earlier study we reported palpable changes in paravertebral tissue in patients with acute myocardial infarction. ${ }^{1}$ We undertook a follow up study to determine whether this somatic component altered as the

Eight of the 25 patients with myocardial infarction who participated in the initial study were available for follow up three to four years later. Of the others, nine had died and eight had moved away or were unwilling

The osteopathic physicians were unaware of the clinical diagnosis and were not allowed to talk to the patients in case this provided them with subjective information. As none of the patients had been admitted to hospital it was not necessary to simulate visual clues of treatment as had been necessary in the first study. The physicians noted palpable changes in the paravertebral soft tissue from $\mathrm{T} 1$ to $\mathrm{T} 8$ that matched predetermined qualitative descriptors, ${ }^{2-4}$ as in the

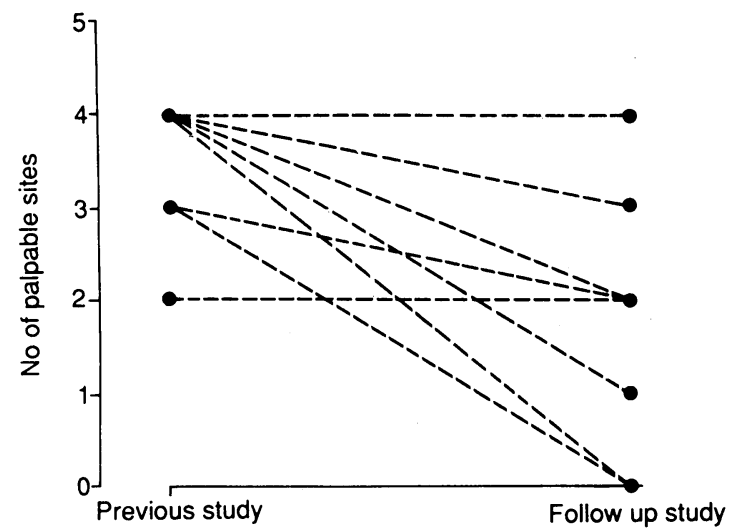

Change in number of palpable sites between $T 1$ and T4 on left side in eight patients with myocardial infarction followed up after three to four years previous study. Changes from $\mathrm{T} 1$ to $\mathrm{T} 4$ and from $\mathrm{T} 5$ to T8 on each side were evaluated statistically with the Wilcoxon matched pair signed rank test. The dif- ferences in the findings between the two studies were 을 ranked and analysed.

The study was approved by the American Osteopathic Association Bureau of Research and the institutional review board of the Philadelphia College of Osteopathic Medicine. Written informed consent was obtained from all subjects.

The number of palpable sites between $\mathrm{T} 1$ and $\mathrm{T} 4$ on the left had fallen in six patients and was the same in two $\left(p<0.05\right.$; figure); the median change was $-1.5 \frac{\bar{\partial}}{0}$ (95\% confidence interval 0 to -4$)$. The other com-气 parisons between the two studies yielded $\mathrm{p}>0 \cdot 2$.

\section{Comment}

Our findings suggest that the somatic component of myocardial infarction and the insult to the myocardium may be anatomically and physiologically related. We are planning a prospective study of patients at high risk. of myocardial infarction to determine whether the 3 somatic changes are present before infarction is clinic-ally apparent. Such an early predictor would speed윽 clinical management and might reduce mortality. The 30 year update of the Framingham study showed that unrecognised myocardial infarction is common $N$ and has a poor prognosis. ${ }^{5}$ Clearer definition of the somatic component could help in the diagnosis of silent myocardial infarction and allow earlier clinicaln intervention.

We are indebted to the following coworkers: We Ehrenfeuchter, D Heilig, K England, and M Kirschbaum. We thank Dr Hyman Menduke for advice on statisticale analyses, Mrs Wanda L Young for computer generated: analyses, and Mrs Christine $M$ Donovan for typing the manuscript.

Nicholas AS, DeBias DA, Ehrenfeuchter W, et al Somatic component myocardial infarction. BrMed $\mathcal{F} 1985 ; 291: 13-7$.

Beal MC. Palparory tesing for somatic dysunction in patients with ardio vascular disease. 7 Am Osteopath Assoc 1983;82:822-31.

Cox JM, Gorbis S, Dick LM, Rogers JC, Rogers FJ. Palpable musulokele findings in coronary artery disease: results of a double blind study J Am Osteopath Assoc 1983;82:832-6.

Beal MC, Kluber GE. Somatic dysfunction as a predictor of coronary artery disease. 7 Am Osteopath Assoc 1985;85(5):302-7.

$5 \mathrm{Kannel}$ WB, Abbott RD. Incidence and prognosis of unrecognized myocardial infarction: an update on the Framingham study. N Engl F Med 1984;311: 1144-7.

(Accepted 20 April 1990) 